\title{
EDIÇÃO E TRANSMISSÃO DO/NO CURSO DE LINGUÍSTICA GERAL
}

Bruno Turra*

https://orcid.org/0000-0001-5243-7245

Como citar este artigo: TURRA, B. Edição e transmissão do/no Curso de Linguística Geral. Todas as Letras - Revista de Lingua e Literatura, São Paulo, v. 22, n. 2, p. 1-18, maio/ago. 2020. DOI 10.5935/1980-6914/eLETDO2013433

Submissão: maio de 2020. Aceite: julho de 2020.

Resumo: A partir da análise de um fragmento do Curso de Linguística Geral, notadamente aquele que trata da escrita no capítulo destinado ao valor linguístico (SAUSSURE, 2002 [1916], p. 138-139), buscarei levantar algumas questões sobre a construção do CLG e do papel de seus editores. Deslocando-me de uma discussão que coloca em pauta a deturpação das palavras do mestre por seus discípulos, lerei a referida passagem do CLG em busca das marcas deixadas pelos editores que transmitem o gesto saussuriano.

Palavras-chave: Saussure. Filologia saussuriana. CLG. Manuscrito. Transmissão.

Fool.

I marvel what kin thou and thy daughters are: they'll have me whipped for speaking true, thou'lt have me whipped for lying; and sometimes I am whipped for holding my peace.

I had rather be any kind o' thing than a fool; and yet I would not be thee, nuncle; thou hast pared thy wit o' both sides, and left nothing i' the middle: here comes one o' the parings.

W. Shakespeare, King Lear

Pesquisador independente, membro convidado do GT Estudos Saussurianos da Anpoll, São Paulo, SP, Brasil. E-mail: bruno.m. turra@ gmail.com 


\section{DA CONSTRUÇÃo DE UM MONUMENTO}

$\boldsymbol{P}$ oucos dias após a morte de Ferdinand de Saussure (23/02/1913), sua viúva, Marie Faesch de Saussure, recebe cartas de dois ex-alunos do mestre genebrino pedindo autorização para a publicação do que chamavam de "sua obra". Charles Bally (01/03/1913), em Genebra, que ocupou a cadeira de Saussure na Universidade após sua morte, e Meillet (06/03/1913), em Paris, que ocupava o cargo destinado a Saussure quando este deixara a cidade duas décadas atrás (SOFIA, 2015, p. XX-XXV).

Não havia, entretanto, um texto a ser publicado, algo que se pudesse chamar de um livro ${ }^{1}$. Eram milhares de folhas de temáticas diversas, cadernos sobre seus exercícios anagramáticos, sobre as lendas germânicas, diários de viagem sobre o lituano, notas sobre a linguística geral. Na disputa pelo comando da publicação, os ex-alunos concordavam sobre o que entendiam por "sua obra": tratava-se dos manuscritos de linguística geral. Discordavam, porém, do método. Enquanto Meillet desejava publicar os manuscritos tais como se apresentavam, em notas, Bally vislumbrava uma obra única, um "todo orgânico", como definiria seu projeto posteriormente. Madame de Saussure, em carta a Meillet de 25 de maio daquele ano, compartilha com o linguista francês sua preferência pela publicação de uma obra única, elaborada a partir dos cadernos dos alunos, projeto semelhante ao de Bally. No dia seguinte, Bally escreve a Meillet explicando seu projeto, e este lhe responde com pesar, se afastando da disputa. A viúva, então, entrega o espólio a Bally.

O livro, lançado em 1916 e cuja autoria é atribuída ao próprio Ferdinand, é o resultado de um trabalho realizado a quatro mãos, com Albert Sechehaye, e que visava a uma espécie de reconstituição dos três cursos de linguística geral ministrados nos três últimos anos letivos do mestre antes de seu afastamento por razões de saúde. Como podemos ler no prefácio do livro publicado, os então editores encontraram uma dificuldade inicial. Saussure não mantinha os registros das aulas, restando apenas folhas esparsas em suas gavetas. Recorreram, portanto, aos cadernos dos alunos que participaram do curso. Tendo por base os cadernos de Albert Riedlinger (cursos I e II) e de G. Dégallier (curso III), contaram também com a contribuição das notas de L. Gautier, F. Bouchardy, F. Joseph e Marguerite Sechehaye.

O trabalho dos editores pode ser dividido em dois momentos, o primeiro, realizado por Albert Sechehaye, de compilação dos cadernos, reagrupamento de conteúdos dispersos nos três cursos e estabelecimento de uma sequência para o encadeamento do material. Esse processo resultou no material que chamamos Collation Sechehaye. Num segundo momento, esse esboço passa, então, por diversas alterações propostas por Bally, tanto na ordem dos capítulos quando na padronização de termos utilizados pelo mestre em seus três anos de curso quanto da inserção de fragmentos deixados de fora pelo colega. Publica-se, assim, o Curso de Linguística Geral (doravante CLG), em 1916.

"A família e os alunos genebrinos de F. de Saussure se encontram diante de um caso de consciência delicado" (MEILLET, 1968 [1916], p. 161]). É dessa forma que Meillet abre seu compte-rendu do CLG ao aproximar o rigor teórico e a

Mesmo o que podemos ler nos manuscritos designados como "Notas para um livro sobre linguística geral" não apresenta uma estrutura de livro, mas de notas esparsas. 
hesitação do mestre genebrino em publicar "suas ideias de forma definitiva" ao trabalho dos suiços de "fundir em um todo as três redações e de construir, por assim dizer, com as fórmulas e os exemplos de F. de Saussure, o livro que o mestre não havia feito, que ele não teria, sem dúvida, jamais feito" (MEILLET, 1968 [1916], p. 162). O texto de Meillet exerceu forte influência sobre os leitores franceses e caracterizou o que Chiss e Puech (1994) nomeiam de primeira recepção do CLG.

Nesse primeiro momento após a publicação do livro, sobretudo na França, o que ali se lia não era reconhecido como sendo do mesmo autor do brilhante Mémoire sur le système primitif des voyelles dans les langues indo-europeénnes, texto publicado por um ainda jovem Saussure durante seus estudos em Leipzig, em 1879. O CLG era visto como lacunar, não sendo fiel ao pensamento do mestre, um livro que Saussure "jamais teria escrito", uma "perversão do Saussure 'real"' (COLOMBAT; FOURNIER; PUECH, 2010, p. 26).

É apenas a partir do I Congresso Internacional de Linguística, em Haia, em 1928, que o CLG surge como "ponto de apoio, alavanca da inovação em linguística" (COLOMBAT; FOURNIER; PUECH, 2010, p. 26), mostrando-se relevante em círculos linguísticos mais distantes de Paris, como Praga e Copenhague. Nas duas décadas seguintes, as ideias veiculadas no CLG passam a ser observadas em textos de linguistas de diversos lugares, inclusive em Paris. O Saussure do Mémoire parece então não fazer mais frente ao Saussure do CLG.

Em 1945, em Nova York, um acontecimento marca o que Colombat, Fournier e Puech (2010) chamam de terceira recepção do CLG. Trata-se da publicação do texto de Ernst Cassirer, "Structuralism in modern linguistics", na revista Word, que também apresentava artigos do linguista R. Jakobson e do antropólogo C. Lévi-Strauss. É a primeira vez que a palavra "estruturalismo" surge num artigo científico. Na França, é M. Merleau-Ponty quem lança as reflexões do CLG para fora dos círculos linguísticos. Em sua aula inaugural no Collège de France, em 1953, o filósofo, ao questionar o papel da língua e do sentido para a filosofia e para a história, atribui a Saussure o esboço de uma nova filosofia da história. Nesse momento, o CLG ganha as ciências ditas humanas, constituindo o que conhecemos hoje como estruturalismo francês, tendo a linguística saussuriana como ciência-piloto.

É ainda durante esse terceiro movimento de leitura do CLG, num diálogo mais amplo com as ciências humanas, que o nome de Saussure se vincula definitivamente ao CLG, numa época de refundação das disciplinas marcada pelo retorno aos pais fundadores (CHISS; PUECH, 1987, p. 8). A Saussure é atribuída a paternidade da linguística. Uma paternidade, portanto, atribuída retrospectivamente. De "perversão" (uma père-version), o CLG passa a figurar como monumento erigido ao pai morto e a funcionar como representante da lei. Ao se produzir tal monumento, algumas simplificações ganharam destaque, como a fixidez das dicotomias e uma suposta exclusão do sujeito.

A quarta e última recepção de Saussure, segundo Colombat, Fournier e Puech (2010), é marcada pela publicação de trabalhos capitais do que chamamos filologia saussuriana. São estes a publicação de Robert Godel, resultado de sua pesquisa doutoral Les sources manuscrites du Cours de Linguistique Générale de F. de Saussure, em 1957 (doravante SM); o hercúleo trabalho de Engler que, em dois volumes (1968-1974), publica uma edição sinóptica do CLG (doravante CLG-E), comparando o livro editado por Bally e Sechehaye com as notas dos 
cadernos dos alunos; e a edição crítica de Tullio De Mauro, cujas notas críticas publicadas originalmente em italiano, em 1967, são incorporadas à edição francesa do CLG em 1972. Esses trabalhos, que atualmente são considerados obras incontornáveis para uma leitura de Saussure, se dedicaram, cada um a seu modo, à comparação e análise dos manuscritos saussurianos com o CLG. Com essas publicações, intensificou-se a investigação das incontáveis folhas manuscritas deixadas pelo mestre genebrino, trazendo à luz manuscritos de temas considerados periféricos pelos editores do curso, como os anagramas (STAROBINSKI, 1974 [1971]) e as lendas germânicas (MARINETTI; MELI, 1986).

Um novo momento de recepção do trabalho saussuriano se esboça a partir de 1996, quando, num aposento da casa da família de Saussure, descobre-se um envelope com anotações até então inéditas. Tratava-se do que hoje conhecemos como "Sobre a essência dupla da linguagem", publicado em 2002 sob o título Escritos de Linguística Geral, juntamente com outros manuscritos já de conhecimento público. No texto descoberto, encontramos um Saussure hesitante, diferente daquele lido no CLG.

A publicação dos novos manuscritos cria um duplo para aquilo que havia se erigido como monumento fundador da linguística moderna. Os manuscritos passavam a reclamar uma autoridade que até então era atribuída ao CLG: opõe-se então um verdadeiro Saussure, o dos manuscritos, a um falso Saussure, o do CLG.

Muitas páginas foram escritas em defesa de uma busca pelo Saussure original, o verdadeiro mestre que ministrou os cursos de linguística geral entre os anos de 1907 e 1911. Por essa via, os editores são tomados como detratores da palavra de seu professor a ponto de se preterir a leitura do livro de 1916.

O percurso de leitura que pretendo esboçar neste texto é outro. A busca por um verdadeiro Saussure é infrutífera na medida em que se perde o lastro da história e se fecha a interpretação em um "Saussure disse que". Minha pergunta é outra: o que podemos dizer hoje a partir da fortuna crítica construída em mais de um século sob o nome "Saussure"? Nesse sentido, a leitura dos manuscritos não se justifica pela busca de uma verdade que se pretenda originária, mas, no contado desses manuscritos com o CLG, o que se pode ler de novo? De novo: repetição e atualidade. É nesse movimento que buscaremos uma leitura de Saussure hoje.

A nosso ver, o gesto de Saussure deve ser compreendido em dois tempos: um de formalização e outro de fundação, tempos que, no caso do genebrino, não coincidem, mas que se reúnem sob seu nome. Seguimos a leitura de Milner quando afirma, em O amor da língua, que para Saussure a linguística já existia, era a gramática comparada, e que sua tarefa seria, então, formalizar o que já se fazia. O gesto fundador foi-lhe atribuído posteriormente, e com referência ao CLG o que implica que se considere o papel dos editores nesse gesto. Em outras palavras, se houve um gesto fundador, deste não se pode subtrair o papel de Bally e Sechehaye. Concordamos, assim, com Silveira (2003, p. 27-28) quando a autora afirma que

[...] a edição é mais que reprodução das ideias de Saussure ou deformação dessas ideias pelos editores, ou seja, houve aí um movimento que é próprio da edição e leva a marca tanto de Saussure quanto dos editores. Falar do estatuto da edição é dizer dessa marca. [...] Assim, se o CLG cumpriu a sua função na 
fundação da linguística geral é porque, embora tenha havido a edição, essa não apagou os efeitos do trabalho de Saussure ao constituir um saber novo sobre a língua.

É precisamente na leitura das marcas de um movimento que me debruçarei. Nessa leitura, busco o que se pode ler enquanto uma transmissão, enquanto aquilo que se transmitiu - e se transmite - sem se subtrair as mãos que fizeram parte desse percurso. Sob essa perspectiva, a autenticidade de um Saussure em detrimento de outro, o do CLG, não se mostra produtiva, uma vez que apaga todo um movimento de leitura e de fundação de uma disciplina, apaga um desenvolvimento teórico que rompeu a barreira da linguística e que não se invalida pela recusa a um livro. Se há um Saussure autêntico nos manuscritos em oposição ao falso do CLG, é, pois,

[...] o Saussure autêntico é necessariamente tributário do Curso. Ele é condenado a acompanhar o Grande Clássico. Ele é um pouco como o bobo da corte que diz a verdade, certamente, mas que, mesmo dizendo a verdade, não possui a força de agitar o Poder, mas, ao contrário, o confirma. Assim, a versão desconstrutiva de Saussure, o Saussure autêntico, etimológico, verdadeiro, não terá força para eliminar a potência do Grande Clássico, tão usurpada, falsa que seja. O Saussure "autêntico" está tragicamente condenado a permanecer o bobo do Curso (TRABANT, 2005, p. 124).

\section{UM EXERCÍcIo DE LEITURA: CLG, P. 138-139}

Tendo apresentado os diferentes movimentos de leitura que foram realizados desde a publicação da obra editada por Bally e Sechehaye e contextualizado as questões que nos são colocadas hoje ao relermos Saussure, proporei um breve exercício de leitura de um fragmento do CLG (SAUSSURE, 2002 [1916], p. 138-139) que trata do papel da escrita na linguística tributária à Saussure.

\section{A questão da escrita}

Há, no Curso de Linguística Geral, dois momentos em que a escrita é posta em questão de maneira mais desenvolvida. O primeiro momento, o capítulo sexto da introdução do livro, intitulado "Representação da língua pela escrita", é inteiramente dedicado ao tema, sobretudo aos problemas enfrentados pelo linguista quando este toma a escrita como objeto de estudo. O segundo momento aparece na segunda parte do livro, destinada à linguística sincrônica, no capítulo quarto, "O valor linguístico", mais especificamente, no parágrafo terceiro, "O valor linguístico considerado em seu aspecto material", em que se aproximam uma série de características do sistema da escrita e da língua. Tais passagens do CLG são emblemáticas, pois é a partir delas que se desenrola um amplo debate sobre a relação que se estabelece, em linguística, entre língua e escrita.

Em poucas palavras, a primeira ocorrência trata da escrita na sua relação com a língua; e a segunda, do funcionamento da escrita enquanto um sistema autônomo ${ }^{2}$. Neste texto, tratarei, não das implicações teóricas do tratamento dado por Saussure à escrita, mas bem especificamente da forma como os editores

2 Para uma melhor apreensão dos dois momentos em que a escrita é tratada no CLG, conferir Turra (2018). 
construíram o fragmento localizado nas páginas 138 e 139 da edição brasileira do CLG.

Vale ressaltar apenas que a leitura que se faz tradicionalmente desses momentos do CLG é de uma descontinuidade, uma vez que, no primeiro momento, a escrita é tida como monstruosidade, deturpadora da lingua, uma representação imperfeita e, no segundo, a escrita funciona como o modelo mesmo de funcionamento da língua. Este momento, em contraste ao que se lê no capítulo sobre a representação da língua pela escrita, é tido como o ponto contraditório (DERRIDA, 2013 [1967]), ou ponto de virada (ARRIVÉ, 2010 [2007]), que passou a matizar a leitura que se fazia da posição saussuriana, sobretudo a partir da proposta gramatológica de Derrida e, depois dele, de seus críticos (Chiss e Puech, Anis, Harris, Testenoire, entre outros).

\section{A costura dos editores}

O fragmento a ser analisado constitui as alíneas de 8 a 12 do parágrafo terceiro, "O valor linguístico considerado em seu aspecto material", do capítulo IV, "O valor linguístico", inserido na segunda parte do livro, "Linguística sincrônica". Tal capítulo tem por objetivo apresentar o que muitos dos estudiosos da obra do genebrino tomam como o cerne de seu trabalho, a teoria do valor. Um dos nomes que seguem esse caminho, com o qual concordo, é Milner (2002, p. 37). Para o autor,

[...] o conceito de signo é de pouco peso na linguística uma vez que ela é constituida: esta última apenas se estabelecerá como ciência ao considerar seu objeto do ponto de vista diferencial e negativo, ora, o signo fecha todo acesso a esse ponto de vista. Saussure também propôs não o nome signo, mas o nome de valor, ao se inspirar na teoria da moeda (cf. CLG, II, 4, §2). De forma que Saussure parte do signo para o abandonar, mas ele somente o pode abandonar por tê-lo colocado em seu ponto de partida.

É, portanto, num dos momentos-chave do CLG que a escrita retorna. Vale observar, porém, que o movimento não é de Saussure, mas dos editores. Seguindo as informações dadas por Godel (1969 [1957], p. 107) e Engler (SAUSSURE, 1968 [1916], p. 255 ss.), observamos que os primeiros dois parágrafos do capítulo, intitulados "A língua como pensamento organizado na matéria fônica" e "O valor linguístico considerado em seu aspecto conceitual", provêm quase que integralmente das últimas aulas do curso interrompido em 1911, apenas com inserções pontuais de material do curso de 1908-1909. O mesmo ocorre com o quarto parágrafo, "O signo considerado na sua totalidade", em que lemos o material das últimas aulas do terceiro curso e, pontualmente, o material do segundo curso e de notas autógrafas de Saussure.

Ao consultarmos a Collation de Sechehaye, vemos que esta segue o terceiro curso anotado por Dégallier até a última página, em que lemos a observação de Bally reproduzida a seguir: 
Figura 1 - Reprodução de fragmento do manuscrito Collation Sechehaye, p. 463. Conservado na BGE, sob a cota Cours univ. 432-433

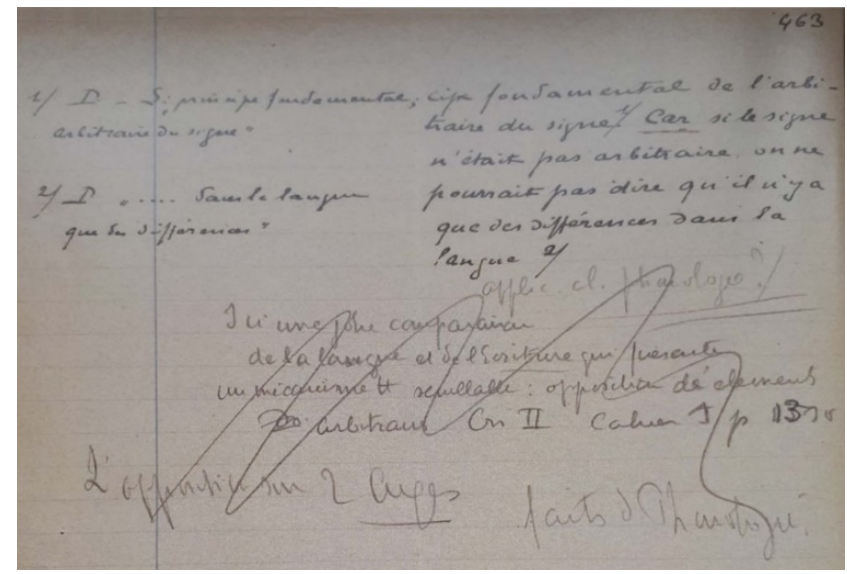

Segundo a transcrição diplomática de Sofia (2015, p. 463, tradução nossa, grifo nosso), temos, no fragmento riscado: "Aqui uma bela comparação da língua com a Escrita que apresenta um mecanismo inteiramente semelhante: oposição de elementos arbitrários Crs II Caderno 1 p. 13 ss"3.

É então a partir dessa observação que os editores retomam o texto do segundo curso em busca da "bela comparação" que dará corpo ao terceiro parágrafo do capítulo do valor, "O valor linguístico considerado em seu aspecto material". O parágrafo não é composto exclusivamente de material do segundo curso. As três primeiras alíneas têm como fonte o material do terceiro curso que seguia aquele utilizado no parágrafo anterior articulado a notas autógrafas de Saussure, de onde se extrai que "Arbitrário e diferencial são duas qualidades correlativas" (SAUSSURE, 2002 [1916], p. 137).

O texto do CLG passa, então, a se fundamentar no segundo curso a partir da quarta alínea, em que os editores trazem da aula do dia 12 de novembro de 1908 mais um exemplo para justificar "o que há de sistemático no jogo de diferenças fônicas", dando continuidade à alínea anterior, proveniente do terceiro curso.

As alíneas 5, 6 e 7 provêm da aula do dia 23 do mesmo mês, em que Saussure buscou estabelecer o lugar do som na relação com a língua. Nesse ponto, a tentativa de promover um todo orgânico dá indícios de sua impossibilidade. Onde se lê, nos cadernos dos alunos, um movimento bastante nuançado, o CLG é categórico. Trazemos a seguir a nota de Constantin, que pode ser lida, com pequenas variações, também nos cadernos de Riedlinger, Gautier e Bouchardy, sendo a do primeiro apenas a mais sintética: "Não se pode tratar a língua sem falar de sons. E, contudo, num certo sentido, o som é estranho à essência da língua" (SAUSSURE, 1968 [1916], p. 266), ao que a pena dos editores escreve "Ademais, é impossível que o som, elemento material, pertença por si à língua" (SAUSSURE, 2002 [1916], p. 137). Os editores então concluem, com base nas notas dos alunos da mesma aula do segundo curso, que

3 "Ici une jolie comparaison de la langue avec l'Écriture qui présente un mécanisme tt. semblable: opposition des éléments arbitraires Crs II Cahier 1 p. 13 sv." 
Ele [o som] não é, para ela [a lingua], mais que uma coisa secundária, matéria que põe em jogo. [...] Isso é ainda mais verdadeiro no que respeita o significante linguístico; em sua essência, este não é de modo algum fônico; é incorpóreo, constituido, não por sua substância material, mas unicamente pelas diferenças que separam sua imagem acústica de todas as outras (SAUSSURE, 2002 [1916], p. 137-138).

De um movimento desde fora, ou seja, da semiologia apresentada no segundo curso, é que Saussure propõe a radical incorporeidade do significante, sendo ele puro valor, e o faz expandindo a noção para os demais sistemas de signos, "não é o metal da moeda que lhe fixa o valor" (SAUSSURE, 2002 [1916], p. 131).

Passemos, enfim, ao fragmento, que se inicia na oitava alínea do parágrafo:

Como se comprova existir idêntico estado de coisas nesse outro sistema de signos que é a escrita, nós o tomaremos como termo de comparação para esclarecer toda a questão. De fato:

$1^{\circ}$ os signos da escrita são arbitrários; nenhuma relação existe entre a letra t e o som que ela designa;

$2^{\circ}$ o valor das letras é puramente negativo e diferencial; assim, a mesma pessoa pode escrever $\mathrm{t}$ com variantes tais como:

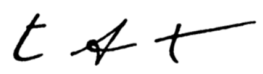

A única coisa essencial é que este signo não se confunda em sua escrita, com o do l, do d etc.;

$3^{\circ}$ os valores da escrita só funcionam pela sua oposição recíproca dentro de um sistema definido, composto de um número determinado de letras. Esse caráter, sem ser idêntico ao segundo, está estreitamente ligado com ele, pois ambos dependem do primeiro. Como o signo gráfico é arbitrário, sua forma importa pouco, ou melhor, só tem importância dentro dos limites impostos pelo sistema; $4^{\circ}$ o meio de produção do signo é totalmente indiferente, pois não importa ao sistema (isso se deduz também da primeira característica). Quer eu escreva as letras em branco ou preto, em baixo ou alto relevo, com uma pena ou com um cinzel, isso não tem importância para a significação (SAUSSURE, 2002 [1916], p. 138-139).

Tal como o texto é apresentado pelos editores, a escrita é trazida à baila para confirmar os pontos nucleares da teoria elaborada por Saussure: 1. a arbitrariedade e a não referencialidade do signo; 2 . seu caráter negativo e diferencial; 3 . a necessidade de um sistema fechado para o funcionamento do signo; e 4. a incorporeidade do significante. Mais do que isso, ao verificar as características do signo linguístico também na escrita, o fragmento legitima o lugar da semiologia como uma ciência mais ampla, que compreenderia os estudos dos diversos sistemas de signos, inclusive a linguística.

O movimento de Saussure aqui é bastante diferente daquele apresentado no capítulo sobre a representação da língua pela escrita. Se lá esta ocupava um lugar secundário, um decalque imperfeito da língua, no capítulo do valor ela é tomada como um sistema de signos com "idêntico estado de coisas". O que fica apagado pelos editores é o local de onde o fragmento foi retirado, de forma que, onde há uma mudança de ponto de vista (no sentido saussuriano do termo), no 
encadeamento do CLG pode-se ler uma retificação, uma reformulação da parte de Saussure com relação ao lugar da escrita.

Entretanto, quando nos debruçamos nas notas dos alunos, tal interpretação, a de uma retificação, parece não se sustentar. Se antes o que interessava a Saussure era a função representativa da escrita, nessa mudança de ponto de vista o genebrino passa a tratar do funcionamento da escrita. Esse novo ponto de vista, apesar de exterior - ou talvez por isso mesmo -, afeta a essência do funcionamento da língua.

\section{Os cadernos dos alunos}

Ao retomarmos as anotações dos alunos de Saussure, observamos alguns deslocamentos promovidos pelos editores. Engler nos indica como fontes do fragmento acima destacado um trecho dos cadernos de Albert Riedlinger (SAUSSURE, 1997 [1908-1909], p. 7-8), além das notas de Léopold Gautier, François Bouchardy e Émile Constantin (C II, p. 12), referentes à aula do dia 12 de novembro de 1908 (cf. GODEL, 1969 [1957], p. 66).

Dessa leitura comparada, destacaremos dois elementos que merecem ser investigados. O primeiro ponto a se destacar é apontado por Arrivé, em Em busca de Ferdinand de Saussure, e diz respeito ao primeiro termo da comparação. Lá onde no CLG encontramos "nenhuma relação entre a letra t e o som que ela designa” (SAUSSURE, 2002 [1916], p. 138), nos cadernos dos alunos, à exceção de Gautier, que não traz anotação a respeito, lemos "não há relação entre o signo e a coisa a designar" (SAUSSURE, 1968 [1916], p. 269). Há uma diferença importante. Para Arrivé (2010 [2007], p. 85),

[...] não é o som que deve ser assumido a título de significado pela letra, mas uma "coisa". Coisa inominável por alguma outra palavra que não seja "coisa": reconhecemos aqui, sem a menor dificuldade, o significante incorpóreo, efetivamente dificil de subtrair de seu resíduo fônico ou gráfico.

A observação de Arrivé reitera a radicalidade do incorpóreo do significante já tratada no CLG e reinsere a questão da contraparte do significante gráfico. Se retomarmos a diferenciação que o próprio Saussure estabeleceu entre os sistemas fonéticos e ideográficos (SAUSSURE, 2002 [1916], p. 36), é o modelo chinês que se aproxima dessa concepção: não é o som, mas a "coisa a designar", a imagem "da coisa” para o falante, que funciona como significado.

O segundo ponto, logo no início do fragmento, diz respeito ao "idêntico estado de coisas". O que os editores estenografam como uma identidade do estado de coisas entre os dois sistemas, em Riedlinger lemos que os sistemas são "similares", já Gautier diz que ambos os sistemas pertencem a "um mesmo domínio" e, finalmente, Bouchardy e Constantin anotam "uma mesma ordem de coisas" (SAUSSURE, 1968 [1916], p. 269). Na Collation, sob a pena de Bally, lemos "mecanismo inteiramente semelhante" ao tratar da "bela comparação". De acordo com o texto, não há, à exceção de Riedlinger, uma comparação entre sistemas distintos com um funcionamento semelhante, o que se pode ler é um mesmo funcionamento presente em sistemas que compartilham uma mesma ordem de coisas. A inversão é sutil, mas em nossa leitura produz efeitos significativos. Em outras palavras, qual tipo de relação que se estabelece entre esses dois sistemas 
de signo? Trata-se de uma relação de analogia ou de homologia? Tomar esse caminho, o da homologia, reinsere a escrita, desde fora, no interior da lingua, no sentido de que ambas compartilham um mesmo funcionamento interno. Em outro momento (cf. TURRA, 2018), detalhei o percurso da interpretação que me faz sustentar a tese de que se trata de uma homologia.

O caminho da analogia também é possível. Por ele, entretanto, a exclusão da escrita parece radical, não funcionando senão como uma "bela comparação". Essa leitura, a meu ver, não se sustenta, ou ao menos não se mostra produtiva para pensar a relação dos dois sistemas, sobretudo quando se investigam tais relações nos demais manuscritos saussurianos como fiz no texto já mencionado.

Ao analisarmos o fragmento dos $t t$ a partir da comparação do que cada aluno anotou na relação com o que se lê no CLG, apesar de ser extremamente produtivo, isso não reinsere o fragmento no momento de sua enunciação, ou seja, o fragmento assim como foi articulado durante a tal aula do segundo curso. A obra de Engler, apesar de nos fornecer grande material de consulta, por obedecer à ordem do CLG tal como foi estabelecida pelos editores, acaba por não evidenciar a ordem dos cursos, fazendo com que o retorno aos cadernos dos alunos permaneça fundamental.

Nesse sentido, retomemos o fragmento utilizado pelos editores, tal como foi anotado nos cadernos de Riedlinger na sequência da aula de 12 de novembro de 1908:

Para atribuir um lugar à linguística, não é necessário tomar a língua por todos seus lados; é evidente que assim diversas ciências, psicologia, fisiologia, antropologia, <gramática e filologia> etc., poderão reivindicar a língua como seu objeto. Essa via analítica nunca levou a nada. Nós seguiremos uma via sintética. Precisa-se tomar o que parece essencial ao sentimento, e então nós poderemos atribuir ao resto seu verdadeiro lugar na língua. É muito difícil? Não é evidente que antes de tudo a língua é um sistema de signos e que se deve recorrer à ciência dos signos que nos mostra em que pode consistir os signos, suas leis etc.? Essa ciência não existe dentre as disciplinas conhecidas. Ela seria a semiologia (sem nenhuma relação à semântica: ciência dos sentidos <das palavras> na língua por oposição a suas formas!) É evidente também que a língua não engloba toda espécie de sistema formado por signos. Uma ciência de signos mais ampla que a linguística deve existir (sistemas de signos: maritimos, dos cegos, surdos-mudos, e enfim <o mais importante:> a própria escrita!) Mas imediatamente é necessário dizer que a língua ocupará o compartimento principal dessa ciência; <ela será seu patrão geral.> Mas o será por acaso, teoricamente ela será apenas um caso particular. <Não se pode dizer o que será essa ciência dos signos, mas > o grupo <de ciências semiológicas $>$ tem o direito de existir tanto quanto a própria linguística que julgamos digna de estudo, e reclama seu lugar de antemão.

Na escrita, temos um sistema de signos similar ao da língua. Suas principais características são:

1) o caráter arbitrário do signo <(não há relação entre signo e coisa a designar);> 2) valor puramente negativo e diferencial do signo. $<$ Ele adquire seu valor apenas pelas diferenças.> (Para t por exemplo em uma mesma pessoa:

$$
T \tau t
$$

mas o que se exige dele é que não seja idêntico a um lou n!) 
3) Os valores da escrita agem apenas como grandezas opostas <em um sistema definido;> elas são opositivas, são valores apenas por oposição. <Há um limite no número de valores.> (Não é de forma alguma igual a 2) mas se resolve bem finalmente no valor negativo. Exemplo: o que é p para um russo será r para um grego etc.)

4) Indiferença total do meio de produção do signo - resulta igualmente de 1) que eu os escreva em branco, preto, baixo ou alto relevo etc., <é indiferente.> Nós encontramos todas essas características na língua:

à 1): a palavra "apfel" é bem capaz de designar [...] à 2) e 3) tudo consiste em diferenças e oposições [...] à 4) <é menos evidente> [...]

Poderíamos levar essa comparação ainda mais longe <até o detalhe $>$ e $<$ também> encontrar analogias entre os sistemas de signos < diferentes da escrita - como o sistema de sinais marítimos - > e o da língua. Sentimos que estamos na mesma ordem de fatos (SAUSSURE, 1997 [1908-1909], p. 7-9, sublinhado do autor; negrito e itálico nossos).

Ao reinserirmos o extrato utilizado pelos editores (em itálico) no encadeamento apresentado no caderno de Riedlinger, observamos que não se trata apenas de uma "bela comparação", como anota Bally na Collation de Sechehaye. Nos cadernos, a referência à escrita se insere na formulação teórica da natureza da língua definida desde o exterior (GODEL, 1969 [1957], p. 66; SAUSSURE ${ }^{4}, 1997$ [1908-1909], p. 17). Ali são indicados os diversos pontos de vista dos quais a língua pode ser observada e estabelece-se uma "ciência mais geral" na qual a linguística estaria inserida, a semiologia ${ }^{5}$.

A forja de uma nova disciplina, mais geral, é fundamental para que Saussure exerça o que ele chamou de sintese, uma extração das leis fundamentais que constituem todos os sistemas de signos, a língua e a escrita incluídas, em oposição ao que acusou ser improdutivo: uma análise, que, em sua concepção, consistiria em abordar o sistema por meio dos diversos pontos de vista possíveis.

Ao compararmos com o primeiro curso, a forma como a escrita comparece no ano seguinte é fundamentalmente distinta. Em 1907, era-nos apresentado o movimento de exclusão da escrita do interior do objeto linguístico, que aqui consideramos crucial para o estabelecimento de uma nova forma de se fazer linguística. Entretanto, esse movimento de exclusão do objeto da linguística não a excluía da linguística, uma vez que haveria, para Saussure, dois eixos semiológicos e que, a cada um, uma linguística seria atribuida: uma linguística da lingua falada e outra da língua escrita. No curso de 1908-1909, a partir da nova disciplina - a semiologia -, a escrita passa a ser entendida como um sistema de signos fora da linguística e, enquanto tal, possuidor de um funcionamento próprio.

No segundo ano de curso, após distinguir e conceituar língua e fala, Saussure introduz um alerta ao linguista ${ }^{6}$ : é a escrita que permite fixar, classificar a língua

4 "Até aqui, tentamos compreender a língua e o lugar da língua, mas por uma tentativa externa, pelo que ela não é: aproximando-a de um sistema de signos [...], ou ainda mais amplamente do valor".

5 No CLG, o trecho está fragmentado e distribuído nas páginas 16 e 24 da edição brasileira, capítulo III, "Objeto da linguística", do qual tratamos mais acima. O trecho em negrito que ressalta a "escrita ela mesma" como sistema de signos "mais importante" não aparece no livro.

6 Isso deve ser enfatizado. O alerta é dirigido para aqueles que buscam tomar a língua enquanto objeto de uma ciência e não para o sujeito falante, o que destaca o movimento de Saussure com a escrita no que diz respeito à constituição da linguística e não à escrita enquanto sistema de signos. 
no tempo, mas "deve-se distinguir cuidadosamente a palavra escrita da palavra falada e que é apenas a palavra falada o verdadeiro objeto da linguística" (SAUSSURE, 1997 [1908-1909], p. 6). Diante dessa questão, Saussure recorre ao antigo amigo e filólogo francês Louis Havet para destacar a relação que este estabelece entre escrita e filologia, de modo que a linguística, ao lançar mão da escrita (como objeto de estudo), se aproximaria da filologia, chegando a incorporar-se a ela, como podemos ler na sequência das notas de Riedlinger:

A importância da escrita <para a língua> não pode ser ignorada. Ela é tal que nos perguntamos se a linguística não é uma ciência filológica. O sr. Louis Havet diz que teríamos visto $<$ a linguística $>$ caminhar constantemente em direção à filologia e se confundir com ela. O Sr. Havet é, antes de tudo, filólogo (latim) mas em linguística merece <também uma grande> consideração (SAUSSURE, 1997 [1908-1909], p. 6).

Na aula seguinte, em 12 de novembro de 1908, Saussure introduz a semiologia e enumera quatro axiomas que regeriam a nova disciplina. Essa dedução axiomática é feita tendo como modelo o sistema da escrita, ao que conclui afirmando que "nós encontraremos todas essas características na língua" (SAUSSURE, 1997 [1908-1909], p. 7). Trata-se justamente do excerto dos tt inserido pelos editores do CLG no capítulo do valor. Aqui a escrita já aparece deslocada: a noção do duplo eixo semiológico presente no primeiro curso não retorna e a escrita volta a figurar como sistema distinto da lingua a fim de preservar esse novo objeto linguístico. Entretanto, a escrita insiste. De sistema subordinado, a escrita retorna servindo de modelo para o estabelecimento das características do sistema linguístico.

Seguindo as notas de Riedlinger, encontramos uma aula inteiramente dedicada à semiologia, em que se questiona: "<Onde terminará a semiologia? É dificil dizer.> Essa ciência verá seu dominio se estender sempre mais" (SAUSSURE, 1997 [1908-1909], p. 10). Aponta-se ainda uma diferença nas relações dos signos dos diversos sistemas a serem estudados pela semiologia, sendo tarefa da nova ciência tipificar essas relações, que podem ser desde "totalmente arbitrária", no caso das línguas, até o ponto em que o caráter arbitrário é abandonado, aproximando-se da noção de símbolo. Uma outra questão ainda surge: "Que se fez que a semiologia não se impõe como ciência à parte?" ao que se responde "É que o sistema principal de signos é a lingua e é apenas estudando os signos da língua que conheceremos seus lados essenciais, sua vida" (SAUSSURE, 1997 [1908-1909], p. 10).

O que queremos mostrar com nossa leitura é que o gesto inicial de Saussure de excluir a escrita do objeto linguístico permite que esta atue no mais fundamental da língua, demonstrando seu funcionamento. Em nossa leitura, é justamente a homologia que se estabelece entre os dois sistemas que permite essa dobra da escrita sobre a língua. É, pois, por compartilharem um cálculo comum, uma escrita sem análogo, que os sistemas em questão se dobram um sobre o outro, a ponto, por exemplo, de serem tomados um como representação do outro $^{7}$. Tais torções só foram possíveis a Saussure, em certa medida, mesmo sem o saber, no plano da semiologia.

7 É a própria homologia a permitir que se diga que a escrita representa a língua, e que isso funcione até certo ponto. 
Nesse sentido, destacamos a importância da semiologia para a relação entre língua e escrita e como isso produz efeitos quando deslocado, como o foi pelos editores. Ao realocarem esse fragmento fundamental para a delimitação da semiologia - o dos $t t$ - no capítulo sobre o valor, Bally e Sechehaye tomam uma decisão editorial e teórica: reforçar os axiomas da linguística por meio de uma "bela comparação" em detrimento de uma maior visibilidade à nova ciência vislumbrada por Saussure, a semiologia.

Se na Introdução os editores compilam as teorizações saussurianas sobre a escrita, formuladas - vale lembrar - num quadro epistemológico de ruptura com a filologia, no capítulo do valor a escrita entra em cena como "termo de comparação" (SAUSSURE, 2002 [1916], p. 138). Como busquei mostrar, a maior parte do capítulo sobre o valor linguístico deriva do terceiro curso, enquanto o fragmento em que Saussure "compara" língua e escrita para reafirmar o caráter do valor nos reenvia ao início do segundo curso, quando a semiologia é introduzida enquanto "uma ciência mais ampla que a linguística [...] [da qual] a língua ocupará o compartimento principal” (SAUSSURE, 1997 [1908-1909], p. 7).

Com tal gesto dos editores, a semiologia fica enfraquecida e reduzida a duas páginas na introdução do livro de 1916, e a escrita, tal como reintroduzida no capítulo do valor, passa a figurar como uma "bela comparação", não mais enquanto sistema privilegiado de uma teoria geral dos signos ao lado da língua. $O$ trabalho dos editores, no entanto, deixa marcas. O próprio efeito de ruptura com o capítulo sobre a representação da língua, quando lido como uma dessas marcas, nos permite uma abertura para pensar a escrita de um outro lugar.

Ao nos remontarmos ao caderno de Constantin nas anotações da mesma aula, além de verificarmos as alterações vocabulares já pontuadas neste artigo, observamos também uma outra interferência dos editores, esta de cunho gráfico. A materialidade gráfica dos tt utilizados pelo mestre como exemplo do funcionamento da teoria do valor no sistema alfabético latino, ou seja, o fato de uma letra ser identificada não por sua forma, mas pela relação que estabelece com as demais letras desse sistema, ganha dimensão de imagem no livro de 1916.

Como podemos ver no destaque da página reproduzida abaixo, as diferentes grafias da letra $t$ compõem a mesma linha do enunciado de que faz parte: 
DOSSIE

Figura 2 - Reprodução de fragmento do manuscrito Cahiers Constantin Cours II, p. 12. Conservado na BGE, sob a cota Ms. fr. 3972-1 f.06

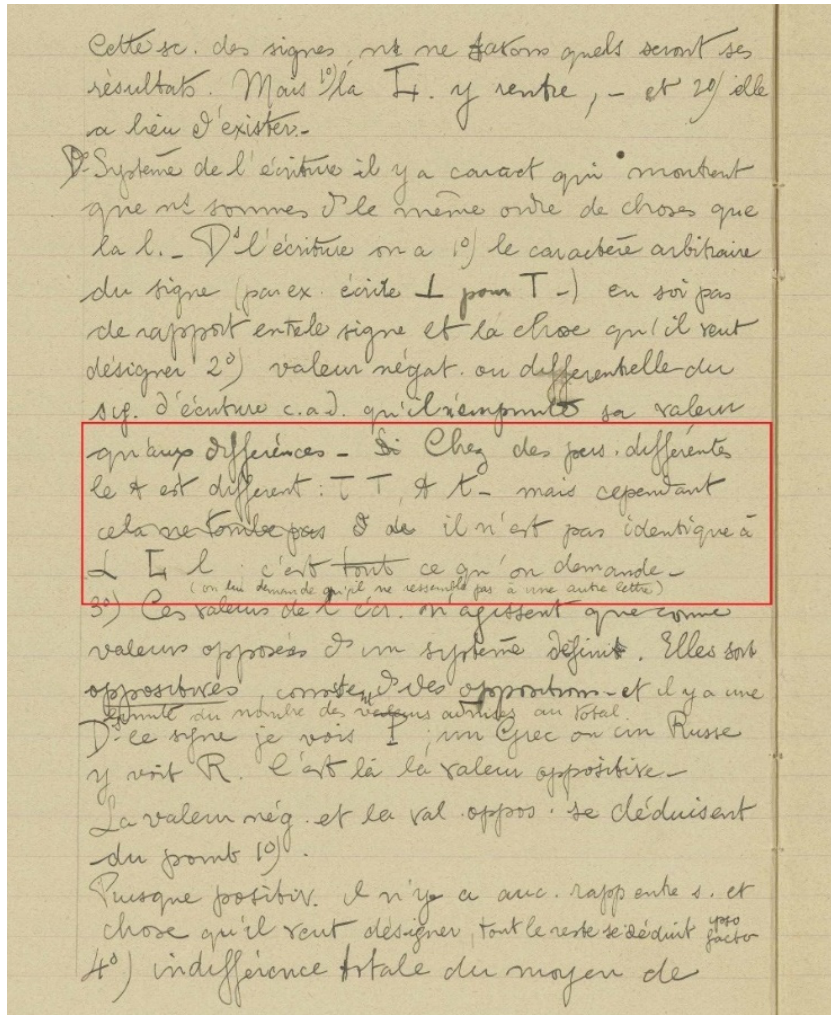

Entre pessoas diferentes, o t é diferente: $\mathrm{T} \tau \mathrm{t}$ - mas entretanto isso não eai em não é idêntico a d, L, l; isso é tudo que se exige. <exige-se que ela não se pareça com outra letra $>^{8}$

Já no trabalho dos editores, estes são destacados do texto e apresentados como imagem:

Figura 3 - Fragmento da página 138 da edição brasileira do Curso de Linguística Geral

\begin{abstract}
Como se comprova existir idêntico estado de coisas nesse outro sistema de signos que é a escrita, nós o tomaremos como termo de comparação para esclarecer toda a questão. De fato:

$1.0^{\circ}$ os signos da escrita são arbitrários; nenhuma relação existe entre a letra $t$ e o som que ela designa;

2.9 o valor das letras é puramente negativo e diferencial;
\end{abstract} assim, a mesma pessoa pode escrever $t$ com variantes tais como:

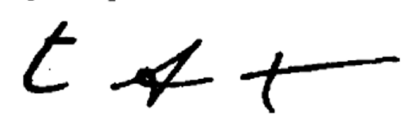

8 "Chez des pers. différentes le $T$ est différent: $T \tau t$-mais cependant cela ne tombe pas d de ce qu'on demande. <on lui demande qu'il ne ressemble pas à une autre lettre>" (tradução minha). 
Há uma alteração: tanto nas notas de Riedlinger quanto nas de Constantin, os $t$ compõem o primeiro período de uma coordenação adversativa e passam, no livro publicado, para o final de um período simples em que a adversativa é desmembrada, iniciando a alínea seguinte. Tal reformulação permite aos editores deslocar os $t$, disponibilizando-os como imagem na página. A interferência dos editores, mais uma vez, produz efeitos. O novo mise en page destaca não apenas um cuidado de Bally e Sechehaye em enfatizar a diferença material dos signos do sistema da escrita, mas também, do ponto de vista do projeto gráfico do livro, alça o fragmento ao nivel das demais imagens da obra.

A "bela comparação" dos editores, recuperada de um fragmento descartado do segundo curso para o que atualmente se considera o ponto central da obra saussuriana, dá corpo a uma discussão sobre a escrita que ocupará filósofos e linguistas já há quase um século. Para Chiss e Puech (1996 [1986], p. 46), por exemplo, é justamente nesse ponto do capítulo sobre o valor que há uma "inversão inesperada" do que Saussure compreenderia como escrita:

Enquanto a lógica do capítulo VI, "Representação da língua pela escrita", deveria levar a situar a escrita em relação à língua, [no trecho acima] é a escrita que "figura" [...] o núcleo da concepção saussuriana da língua, isto é, a teoria do valor.

Apesar de nos aproximarmos da interpretação dos autores, nossa leitura evitaria o termo "inversão", uma vez que se trata de pontos de vista distintos, objetos distintos, portanto. A escrita do capítulo vi não é a mesma escrita que encontramos no trecho sobre a teoria do valor ou, mesmo fazendo uma leitura cronológica, ambos os pontos de vista podem ser observados no segundo curso, não havendo, assim, uma sucessão de concepções de escrita, mas a escrita tomada sob diferentes pontos de vista.

Na leitura de Derrida, por outro lado, Saussure defenderia a subordinação/ exterioridade da escrita em relação à lingua durante todo o CLG. Seria, porém, justamente no capítulo vi da "Introdução" que este daria margem, na interpretação do filósofo, para questionar o lugar atribuído à escrita.

A edição de Bally e Sechehaye, como qualquer trabalho editorial, com seus cortes, torções e deslocamentos, não apaga o fazer de Saussure com a escrita. É fundamentalmente a partir do fragmento realocado no capitulo do valor que Chiss e Puech (1996 [1986]) leem uma alternativa para se pensar, com Saussure, a escrita para além da representação. É enquanto operação de formalização que a escrita assumiria um papel no capítulo do valor. Para os autores:

De fato, se a língua é apenas 'uma máscara arbitrariamente construída e que não atinge real algum' (Saussure, 1972, p. 24), por qual outro meio senão por uma escrita mostrar suas características próprias, suas divisões, suas operações? Vemos assim o que sugere em termos fundamentais o capítulo sobre o valor, e que poderíamos resumir com a fórmula lapidar extraida de M. Safouan: "Para saber como é feita a língua é preciso em primeiro lugar escrevê-la e não o inverso" (1982, p. 29). Se convém extrair as implicações metodológicas dessa tese, podemos também dar-lhe sua extensão máxima: 'A linguagem não seria o que é se não implicasse (a título de consequência e não, como parece ser a tese de Jacques Derrida, a título de origem, de essência ou de causa formal) a possibilidade da escrita' (1982, p. 7) (CHISS; PUECH, 1996 [1986], p. 49). 
Nesse sentido, a homologia que sustentamos haver entre os dois sistemas nos possibilita pensar a proposta de Chiss e Puech como essa dobra da escrita, desde fora, ao estrutural da língua. Essa dobra, porém, se dá a partir disso que o psicanalista Moustafa Safouan, trazido pelos autores, considera uma consequência da linguagem, o fato de esta implicar a possibilidade da escrita, uma proposição que parece estenografar o movimento que lemos em Saussure de uma delimitação exterior da escrita, mas que não exclui um dentro.

Também na leitura de Harris (2000), linguista inglês que dedicou grande parte de sua obra ao estudo da escrita e também tradutor da versão inglesa do CLG, o fragmento dos tt é fundamental para instaurar uma nova forma de pensar a escrita no Ocidente. O linguista inglês acredita ser justamente essa a passagem-chave em que o

[...] estruturalismo faz sua entrada no scriptorium ocidental, em um momento cuidadosamente escolhido e com um objetivo bem específico em vista [...] Então se, apesar da natureza "material" da escrita, pode-se mostrar que o valor formal do signo escrito é puramente negativo, expandir essa conclusão para o signo linguístico seria um corolário natural (HARRIS, 2000, p. 49-50).

O momento escolhido e o objetivo específico a que se refere Harris são justamente o parágrafo "O valor linguístico considerado em seu aspecto material” e a necessidade de sustentar o caráter puramente negativo do signo. Ao atribuir esse status ao signo escrito - puramente negativo e diferencial - Saussure reforça a crítica que faz desde o início de seu ensino a Bopp e seus antecessores, e que Harris estende a Platão, de que não se distinguiam letras e sons. Para Harris, esta é uma crítica não apenas a uma visão de escrita, mas a todo um pensamento acerca da língua(gem) [language, no original]. Na interpretação do linguista inglês, "não é apenas uma questão de corrigir uma visão equivocada da escrita, mas de organizar todo nosso pensamento sobre a linguagem [language]. A semiologia da escrita é sobre muito mais que a escrita" (HARRIS, 2000, p. 52).

\section{Por uma leitura do gesto (de uma conclusão possível)}

Neste texto, busquei me inscrever numa forma de ler Saussure, numa filologia saussuriana que se afasta da busca pelo verdadeiro Saussure, aquele que proferiu as aulas de linguística geral. Aquele texto, oral, está desde sempre perdido. Algo desse Urtext (cf. TESTENOIRE, 2010) da linguística moderna se transmite e de sua transmissão não apenas um livro se estabelece, mas se torna a pedra de toque de um movimento que extrapola o campo linguístico e influencia as ciências humanas de forma decisiva. De Saussure aos saussurismos, sua palavra transmitida e apreendida de diversas maneiras em diferentes partes do globo produziu uma fortuna critica que não pode ser ignorada na busca desse objeto irrecuperável.

Em seu texto "Faut-il défendre Saussure contre ses amateurs?", Trabant (2005) propõe uma maneira interessante de conceber o corpus saussuriano. Para o linguista frankfurtiano, os manuscritos funcionam como o bufon, o fool, o bobo da corte do CLG. Ele aponta as verdades do CLG, mas sem a força para tomar seu lugar. Ao contrário, funciona justamente para confirmar o CLG como acontecimento fundador de um discurso. Ou, se ouvirmos o bobo, "I had rather 
be any kind o' thing than a fool; and yet I would not be thee, nuncle", apesar de ser esta uma posição dificil de se sustentar, antes ela que ser rei.

Uma empreitada que se destine ao que "Saussure quis dizer" não me parece produtiva se se cola esse suposto dizer a uma verdade. É precisamente na relação entre o bobo e Lear, como nos ensina Shakespeare, que algo se produz, que algo se precipita não como verdade, mas como saber. É esse o movimento de leitura que acredito ser produtivo: uma leitura entre o manuscrito e o curso. É desse movimento que algo pode ser produzido na forma de um saber, na forma de algo que produza deslocamentos, reformulações, releituras, e não como da ordem de uma verdade que se fecha sobre si. Saussure não precisa ser defendido de seus editores-detratores. Saussure deve ser lido com seus editores para que disso algo se produza.

Neste artigo busquei mostrar como uma interferência dos editores - o deslocamento do fragmento que tratava da semiologia para o momento do CLG em que se propunha a teoria do valor - produziu efeitos tanto no campo da linguística, como em Hjelmslev, Anis, Harrys e também nas ciências humanas de um modo mais geral, como em Derrida. Em outras palavras, em uma leitura da qual o CLG não é preterido (tampouco mantido como monumento absoluto, tal como era nos anos 1950-1960) e que se articula com a verdade dos manuscritos, nos dá a ver o gesto de Saussure, seu traço, aquilo que apesar (ou por conta) dos editores passa e faz fazer no estabelecimento de um campo, a linguística.

\section{Edition AND transmission of/in the Course of General Linguistics}

Abstract: By the analysis of a fragment of the Course of General Linguistics, specifically that about writing in the chapter reserved for the linguistic value (SAUSSURE, 2002 [1916], p. 138-139), I would like to raise some questions about how the CGL was designed as well as the role of the editors on it. Detaching myself from a discussion that considers the work of the editors as a disfiguration of their professor's words, I am reading the aforementioned fragment looking for traces left by the editors that transmit the Saussurean gesture.

Keywords: Saussure. Saussurean philology. CGL. Manuscript. Transmission.

\section{REFERÊNCIAS}

ARRIVÉ, M. Em busca de Ferdinand de Saussure. São Paulo: Parábola Editorial, 2010 [2007].

CHISS, J. L.; PUECH, C. O Cours de Linguistique Générale e a representação da língua pela escrita. In: CATACH, N. (org.). Para uma teoria da lingua escrita. São Paulo: Ática, 1996 [1986].

CHISS, J. L.; PUECH, C. Fondation de la linguistique: études d'histoires et d'épistémologie. Bruxelles: De Boeck-Wesmael, 1987.

CHISS, J. L.; PUECH, C. F. de Saussure et la constitution d'un domaine de mémoire pour la linguistique contemporaine. Langages, 28e année, n. 114, p. 41-53, 1994.

COLOMBAT, B.; FOURNIER, J. M.; PUECH, C. Histoire des idées sur le langage et sur les langues. Paris: Klincksieck, 2010. 
DE MAURO, T. Notes biographiques et critiques sur F. de Saussure. In: SAUSSURE, F. de. Cours de Linguistique Générale. Edição de Charles Bally e Albert Sechehaye, Genebra: Payot, 2005 [1967]. p. 319-404.

DERRIDA, J. Gramatologia. São Paulo: Perspectiva, 2013 [1967].

GODEL, R. Les sources manuscrites du Cours de Linguistique Générale de F. de Saussure. Genebra: Droz, 1969 [1957].

HARRIS, R. Rethinking writing. London: The Athlone Press, 2000.

MARINETTI, A.; MELI, M. Ferdinand de Saussure - Le leggende Germaniche. Scritti scelti e annotati a cura de Anna Marinetti e Marcelo Meli. Padova: Libreria editrice Zielo di Este, 1986.

MEILlET, A. Compte-rendu du Cours de Linguistique Générale. Bulletin de la Société de Linguistique de Paris, tome XX, n. 65. In: MOUNIN, G. Ferdinand de Saussure. Philosophes de tous les temps. Paris: Éd. Seghers, 1968 [1916]. p. 161-168.

MILNER, J.-C. O amor da lingua. Campinas: Editora da Unicamp, 2012 [1978].

MILNER, J.-C. Le périple structural: figures et paradigme. Paris: Seuil, 2002.

SAUSSURE, F. de. Cours de Linguistique Générale. Edição crítica de R. Engler. Wiesbaden: Otto Harrassowitz, 1968 [1916]. Tomo 1.

SAUSSURE, F. de. Deuxième Cours de Linguistique Générale. D’après les cahiers d'Albert Riedlinger et Charles Patois. Edição de Eisuke Komatsu e George Wolf. Amsterdam: São Paulo: Elsevier, 1997 [1908-1909].

SAUSSURE, F. de. Curso de Linguística Geral. Organizado por Charles Bally e Albert Sechehaye. Tradução Antônio Chelini, José Paulo Paes e Izidoro Blikstein. São Paulo: Cultrix, 2002 [1916].

SAUSSURE, F. de. Escritos de Linguística Geral. Edição de R. Engler e S. Bouquet. Tradução Carlos A. L. Salum e Ana Lucia Franco. São Paulo: Cultrix, 2012.

SILVEIRA, E. M. As marcas do movimento de Saussure na fundação da linguística. 2003. Tese (Doutorado em Linguística) - Universidade Estadual de Campinas, Campinas, 2003.

SOFIA, E. (ed.). La 'Collation Sechehaye' du 'Cours de Linguistique Générale' de Ferdinand de Saussure. Edição, introdução e notas de Estanislao Sofia. Leuven, Paris, Bristol: Peeters, 2015.

STAROBINSKI, J. As palavras sob as palavras. São Paulo: Perspectiva, 1974 [1971].

TESTENOIRE, P. Y. Genèse d'un principe saussurien: la linéarité. Revue Recto/ Verso, n. 6, set. 2010. Disponivel em: https://hal.archives-ouvertes.fr/hal-013 95909. Acesso em: jun. 2018.

TRABANT, J. Faut-il défendre Saussure contre ses amateurs? Notes item sur l'étymologie saussurienne. Langages, n. 159, p. 111-124, 2005. Disponível em: www.persee.fr/doc/lgge_0458-726x_2005_num_39_159_2655. Acesso em: jun. 2018.

TURRA, B. Ferdinand de Saussure e seu saber fazer com a escrita ou do que se circunscreve de um enigma. 2018. 225 f. Tese (Doutorado em Linguística) Universidade Estadual de Campinas, Campinas, 2018. 